\title{
Psychoactive substances use and associated factors among middle and high school students in the North Center of Morocco: a cross-sectional questionnaire survey
}

B. Zarrouq ${ }^{1,2 *}$, B. Bendaou ${ }^{1,2}$, A. El Asri ${ }^{1,2}$, S. Achour ${ }^{3}$, I. Rammouz 4 , R. Aalouane ${ }^{4}$, B. Lyoussi', S. Khelafa ${ }^{5}$, A. Bout ${ }^{5}$, N. Berhili ${ }^{5}, \mathrm{H} . \mathrm{Hlal}^{5}$, A. Najdi', C. Nejjari ${ }^{1}$ and K. El Rhazi ${ }^{1}$

\begin{abstract}
Background: Data on psychoactive substance (PAS) consumption among adolescents in the North Center of Morocco are not at all available. Therefore, the current study aimed at investigating the prevalence and the determinants of psychoactive substances use among middle and high school students in this region.

Methods: A cross-sectional study was conducted from April 2012 to November 2013 in public middle and high schools in the North Central Region of Morocco. An anonymous self-administered questionnaire was used to assess psychoactive substances use among a representative sample of school students from the 7th to the 12th grade, aged 11-23 years, selected by stratified cluster random sampling. Factors associated with psychoactive substance use were identified using multivariate stepwise logistic regression analyses.
\end{abstract}

Results: A total of 3020 school students completed the questionnaires, $53.0 \%$ of which were males. The overall lifetime smoking prevalence was $16.1 \%$. The lifetime, annual and past month rates of any psychoactive substance use among the study subjects were $9.3,7.5$, and $6.3 \%$ respectively. Cannabis recorded the highest lifetime prevalence of $8.1 \%$, followed by alcohol $4.3 \%$, inhalants $1.7 \%$, psychotropic substances without medical prescription 1.0, cocaine 0.7 , heroine 0.3 , and amphetamine with only $0.2 \%$. Psychoactive substance use was associated with males more than females. The risk factors identified by multivariate stepwise logistic regression analyses were being male, studying in secondary school level, smoking tobacco, living with a family member who uses tobacco, and feeling insecure within the family.

Conclusions: The prevalence among all school students reported by the current study was comparable to the national prevalence. Efforts to initiate psychoactive substance prevention programs among school students should be made by designing such programs based on the significant factors associated with psychoactive substance use identified in this study.

Keywords: Prevalence, Psychoactive substance, Risk factors, Secondary school, School students, Morocco

\footnotetext{
* Correspondence: b.ensfes@gmail.com

'Laboratory of Epidemiology, Clinical Research, and Health Community,

Faculty of Medicine and Pharmacy, Sidi Mohammed Ben Abdallah University,

Fez, Morocco

²Laboratory of Physiology-Pharmacology and Environmental Health, Dhar El

Mahraz Faculty of Sciences, Sidi Mohammed Ben Abdallah University, Fez,

Morocco

Full list of author information is available at the end of the article
} 


\section{Background}

Globally, it was estimated that a total of 246 million people, or 1 out of 20 people between the ages of 15 and 64 years, had used an illicit drug in 2013. The magnitude of the world drug problem becomes more apparent when considering that more than 1 out of 10 drug users is a problem drug user, suffering from drug use disorders or drug dependence [1].

In developing countries, recent trends indicate that the use of psychoactive substances (PASs) have dramatically increased [2]. In Morocco, limited information is available on the epidemiology of substance use. The national survey conducted among the general population on mental disorders and addiction in 2003 and 2006 found that the prevalence of PASs consumption for people aged more than 15 was $4.1 \%$ [3]. According to the annual report of the National Observatory of drugs and addictions, cannabis was the most common illegal drug used by Moroccan adolescents in 2013 [4].

In fact, Morocco is one of the main producers of cannabis resin (hashish) in the world despite the intensified efforts of the authorities to decrease the area under cultivation (134,000 ha in 2003 to 47,196 ha in 2013) [1, 5]. The Rif Mountains of the Northern Region is the main area of cannabis cultivation in Morocco [6]. According to the Morocco cannabis survey (2005), $86.0 \%$ of cannabis cultivation was concentrated in three Northern provinces namely Chefchaouen (50.0), Taounate (19.0) and Al Hoceima (17.0 \%) [7].

Albeit the development of the cannabis economy in the Northern provinces of Morocco, no study has been conducted to determine the prevalence and the risk factors related to cannabis and other PASs use among adolescents in this region. Therefore, we conducted a cross sectional survey to estimate the prevalence and the determinants of cannabis and PASs use among middle and high school students in the North Center of Morocco.

\section{Methods}

Study design

A cross-sectional study, targeting students in public middle and high schools of the North central region of Morocco (Fez-Boulemane and Taza Taunate El Hoceima regions), was conducted from April 2012 to November 2013.

\section{Sampling method}

The national survey conducted in 2006 estimated that the lifetime prevalence of PASs use among Moroccan school students was $6.0 \%$ [8]. Henceforth, we calculated the minimum sample size to estimate the prevalence for $95 \%$ confidence limits at an allowable error of $10 \%$. For sample size estimation under cluster sampling, we considered a value of 2 for design effect. The main components of the design effect are the intraclass correlation, and the cluster sample sizes. In practice, when the cluster sample sizes are between 20 to 50 , the intraclass correlation is kept very small. The design effect values available from published reports (e.g., Demographic and Health Survey reports) reported that usually a value of 2 for design effect is considered for sample size estimation under cluster sampling [9]. As a result, we came up with a minimum sample size of 2860 participants.

The list of schools in the North central region was obtained from the Statistical Office of the Ministry of National Education. The schools were split into seven geographical regions and classified into two strata: urban and rural. Forty four middle schools and twenty four high schools were randomly selected. The clusters were defined as classes in each selected school, and all the students of the clusters were involved in the survey. The total cluster selection was done in proportion with the distribution of the schools in urban and rural areas and according to the distribution of students in middle and high schools. This study was conducted according to the guidelines of the Helsinki Declaration.

\section{Data collection}

A questionnaire was developed by reviewing the relevant literature (Additional file 1). The questions were divided into three sections: (i) a socio-demographic background; (ii) smoking tobacco; (iii) and alcohol and PASs use. All participants were asked about their use of tobacco, alcohol, cannabis, psychotropic substances without medical prescription, cocaine, heroin, amphetamine and inhalants (glue, solvents, and aerosols).

Tobacco use was defined according to the International Union against Tuberculosis and Lung Diseases Guide [10]. Lifetime PASs use was also defined as having ever used at least one of the PASs listed in the questionnaire. Past twelve months PASs use was defined as having used the PASs listed in the questionnaires during the 12 months prior to the date of data collection. The current prevalence of PASs use was defined as the proportion of students who used PASs in 30 days preceding the study. At last, Poly-substance use was defined as the regular use of at least two PASs listed in the questionnaire.

\section{Procedures}

The participation in the presented study was entirely voluntary and full confidentiality of the responses was maintained after a clear explanation of the objectives. The absence of any school personnel or teacher at the time of data collection was ensured inside the classrooms to prevent any response bias.

After explaining the instructions for questionnaires' completion, the five investigators who were resident doctors in psychiatry encouraged participants to work individually, quietly, honestly, and as quickly as they 
could. The time given for participants to fill the questionnaire was from $30 \mathrm{~min}$ to an hour.

\section{Data quality control and analysis}

The data entry stage started immediately after finishing data collection. The data were entered into MS Windows Excel in the form of codes, and transferred to Statistical Package for Social Sciences SPSS version 20 (SPSS Inc., Chicago, IL, USA). Data analysis involved descriptive statistics as well as univariate and multivariate analysis. Descriptive statistics involved frequencies, and proportion for categorical variables including cross tabulations. Univariate associations between PAS use and sociodemographic variables and tobacco use were assessed using the chi-square test. Variables with $P \leq 0.20$ on univariate analysis were entered in multivariate stepwise logistic regression model to investigate the risk factors of PAS use. The HosmerLemeshow goodness-of-fit test was used to evaluate multivariate model fit (higher $\mathrm{p}$ values indicate better fit of the model). $P$ values of $<0.05$ were considered as statistically significant.

\section{Results}

\section{Socio-demographic characteristics}

Out of the 3170 students who participated in the study, 3020 completed the questionnaires (at a response rate of $95.0 \%$ ). About $54.9 \%$ of participants were from middle school; while, $45.1 \%$ were from high school. More males $(53.0 \%)$ than females $(47.0 \%)$ participated in this study, and the average age was 16 years ( $\mathrm{SD} \pm 2$ years). As shown in Table 1, 24.7 of surveyed students lived in a rural environment and $75.3 \%$ in urban areas. Regarding parent's marital status, the majority of parents were married $(89.3 \%)$. Concerning parents' education, nearly 35.9 of participants' fathers and $60.6 \%$ of mothers were illiterate; only $11.0 \%$ of fathers and $5.0 \%$ of mothers held university degrees. Regarding family income, most students $(76.9 \%)$ were from medium income families; $88.4 \%$ of students' fathers were employed whereas, $90.5 \%$ of students' mothers were unemployed.

\section{Tobacco use}

Overall, the lifetime smoking prevalence among all school students was $16.1 \%$ (95 \% CI: $14.8 \%$ - 17.4 \%) (Table 2). The prevalence of current smokers was $9.1 \%$ (95\% CI: $8.1 \%-10.2 \%$ ), with mean consumption of 6.5 cigarettes $(\mathrm{SD}=6.1)$ per day. Male students were more likely to current smoke than females $(15.0 \%$ vs. $2.5 \%, p<0.001)$. The mean age at which the school students started smoking cigarettes was 13.9 years ( $\mathrm{SD} \pm 2.5$ years).

\section{Psychoactive substances use}

The overall lifetime prevalence of any PAS use among the study subjects was $9.3 \%$ (95 \% CI: $8.4 \%-10.5 \%$ ).
Table 1 Some selected background characteristics of the study population $(n=3020)$

\begin{tabular}{|c|c|c|}
\hline Characteristics & $N$ & $\%$ \\
\hline \multicolumn{3}{|l|}{ Gender } \\
\hline Boys & 1602 & 53.0 \\
\hline Girls & 1418 & 47.0 \\
\hline \multicolumn{3}{|l|}{ Age groups (years) } \\
\hline $11-14$ & 795 & 26.4 \\
\hline $15-18$ & 1857 & 61.7 \\
\hline $19-23$ & 357 & 11.9 \\
\hline \multicolumn{3}{|l|}{ School levels } \\
\hline Middle school & 1657 & 54.9 \\
\hline High school & 1363 & 45.1 \\
\hline \multicolumn{3}{|l|}{ Location of school } \\
\hline Urban & 2273 & 75.3 \\
\hline Rural & 774 & 24.7 \\
\hline \multicolumn{3}{|l|}{ Parents' marital status } \\
\hline Married & 2684 & 89.3 \\
\hline Divorced & 109 & 3.7 \\
\hline Widowed & 145 & 4.9 \\
\hline Separated & 65 & 2.1 \\
\hline \multicolumn{3}{|l|}{ Father's education } \\
\hline Illiterate & 1065 & 35.9 \\
\hline Primary & 806 & 27.2 \\
\hline Secondary & 767 & 25.9 \\
\hline University and above & 326 & 11.0 \\
\hline \multicolumn{3}{|l|}{ Mother's education } \\
\hline Illiterate & 1813 & 60.6 \\
\hline Primeray & 514 & 17.2 \\
\hline Secondary & 517 & 17.3 \\
\hline University and above & 149 & 5.0 \\
\hline \multicolumn{3}{|l|}{ Father employment } \\
\hline Employed & 2490 & 88.4 \\
\hline unemployed & 82 & 2.9 \\
\hline Retired & 245 & 8.7 \\
\hline \multicolumn{3}{|l|}{ Mother employment } \\
\hline Employed & 281 & 9.5 \\
\hline unemployed & 2688 & 90.5 \\
\hline \multicolumn{3}{|l|}{ Family income } \\
\hline$\leq 300 £$ & 498 & 16.8 \\
\hline $301-1000 £$ & 2280 & 76.9 \\
\hline$\geq 1000 £$ & 187 & 6.3 \\
\hline
\end{tabular}

Males were more likely than females to use PASs (15.7 \% vs. $2.1 \%, p<0.001)$. The last 12 months and the last 30 days prevalence of PASs use among school students were 7.5 and $6.3 \%$ respectively. 
Table 2 Prevalence of tobacco and psychoactive substance use among middle and high school students by gender

\begin{tabular}{|c|c|c|c|c|c|c|}
\hline \multirow{2}{*}{$\begin{array}{l}\text { Tobacco and } \\
\text { psychoactive } \\
\text { substance use }\end{array}$} & \multicolumn{2}{|c|}{ Male $(n=1588)$} & \multicolumn{2}{|c|}{ Female $(n=1405)$} & \multicolumn{2}{|c|}{ Total $(n=2993)$} \\
\hline & $N$ & $\%$ & $N$ & $\%$ & $N$ & $\%$ \\
\hline \multicolumn{7}{|l|}{ Tobacco } \\
\hline Lifetime & 416 & 26.2 & 69 & 4.9 & 485 & 16.1 \\
\hline Last 12 months & 240 & 15.0 & 35 & 2.5 & 275 & 9.1 \\
\hline Last 30 days & 159 & 10.0 & 17 & 1.2 & 176 & 5.9 \\
\hline \multicolumn{7}{|c|}{ Psychoactive substances } \\
\hline Lifetime & 250 & 15.7 & 30 & 2.1 & 280 & 9.3 \\
\hline Last 12 months & 207 & 13.0 & 17 & 1.2 & 224 & 7.5 \\
\hline Last 30 days & 175 & 11.0 & 13 & 0.9 & 188 & 6.3 \\
\hline \multicolumn{7}{|l|}{ Cannabis } \\
\hline Lifetime & 215 & 13.5 & 27 & 1.9 & 242 & 8.1 \\
\hline Last 12 months & 185 & 11.6 & 16 & 1.1 & 201 & 6.7 \\
\hline Last 30 days & 156 & 9.8 & 13 & 0.9 & 169 & 5.6 \\
\hline \multicolumn{7}{|l|}{ Alcohol } \\
\hline Lifetime & 119 & 7.5 & 10 & 0.7 & 129 & 4.3 \\
\hline Last 12 months & 105 & 6.6 & 6 & 0.4 & 111 & 3.7 \\
\hline Last 30 days & 93 & 5.8 & 4 & 0.2 & 97 & 3.2 \\
\hline \multicolumn{7}{|l|}{ Inhalants } \\
\hline Lifetime & 48 & 3.0 & 2 & 0.2 & 50 & 1.7 \\
\hline Last 12 months & 45 & 2.8 & 1 & 0.1 & 46 & 1.5 \\
\hline Last 30 days & 35 & 2.2 & 1 & 0.1 & 36 & 1.2 \\
\hline
\end{tabular}

Psychotropic substances without medical prescription

\begin{tabular}{lllllll} 
Lifetime & 29 & 1.8 & 1 & 0.1 & 30 & 1.0 \\
Last 12 months & 27 & 1.7 & 1 & 0.1 & 28 & 0.9 \\
Last 30 days & 20 & 1.2 & 1 & 0.1 & 21 & 0.7 \\
$\begin{array}{llllll}\text { Cocaine } \\
\text { Lifetime }\end{array}$ & 18 & 1.1 & 2 & 0.1 & 20 & 0.7 \\
Last 12 months & 18 & 1.1 & 2 & 0.1 & 20 & 0.7 \\
Last 30 days & 11 & 0.7 & 0 & 0.0 & 11 & 0.4 \\
Heroine & & & & & & \\
Lifetime & 7 & 0.4 & 1 & 0.1 & 8 & 0.3 \\
Last 12 months & 6 & 0.3 & 1 & 0.1 & 7 & 0.2 \\
Last 30 days & 3 & 0.2 & 0 & 0.0 & 3 & 0.1 \\
Amphetamine & & & & & & \\
Lifetime & 5 & 0.3 & 0 & 0.0 & 5 & 0.2 \\
Last 12 months & 5 & 0.3 & 0 & 0.0 & 5 & 0.2 \\
Last 30 days & 2 & 0.1 & 0 & 0.0 & 2 & 0.1 \\
\hline
\end{tabular}

Table 2 provides the lifetime, the last 12 months, and the current prevalence of PAS use among males and females participants. Cannabis recorded the highest lifetime prevalence with $8.1 \%$, followed by alcohol (4.3\%), inhalants (1.7\%), psychotropic substances without medical prescription (1.0), cocaine (0.7), heroine $(0.3)$, and amphetamine with only $0.2 \%$. In general, the rate of poly drug use (two or more PASs) was $30.0 \%$.

The mean age at which the respondents started using PASs was 14.6 years ( $\mathrm{SD} \pm 2.5$ years). The majority of the school students (37.1\%) started using PASs out of curiosity; while, $34.4 \%$ consumed it to reach certain degree of happiness or pleasure; indeed, $27.7 \%$ admitted using PASs to overcome family problems; $23.0 \%$ considered it helpful to get over personal problems; whereas, $19.1 \%$ stated that they did it because of peer pressure.

\section{Univariate and multivariate analysis}

As shown in Table 3, statistically significant associations $(P<0.05)$ were observed between the PASs status, age groups, school levels, and family income. The PASs use prevalence was higher among high school students (13.4\%), especially in participants aged 19-23 years (22.4\%), and proved lower among students from medium income families (8.4\%). No significant associations were observed in relation to the students' locations (urban or rural areas), parents' marital status, fathers or mothers education, and fathers or mothers employment.

Potential risk factors of PASs use were displayed in Table 4. These factors involved gender, school level, age group, smoking tobacco status, friends and family member smoking status, and feelings of insecurity within family. Univariate analyses revealed that all of the previously stated factors exhibited highly significant statistical associations $(P<0.002)$, with odd ratios ranging from 1.9 (95 \% CI: $1.3-3.0)$ for friends who smoke to 46.6 (95 \% CI: 33.4- 65.2) for smoking tobacco status.

In multivariate logistic regression analysis, age group exhibited statistically non-significant association. The risk factors identified by the multivariate stepwise logistic regression analysis were being male (OR: 1.9; $95 \%$ CI: 1.1 - 2.7), studying in secondary school (OR: 2.8; 95 \% CI: 1.6 - 4.8), smoking tobacco (OR: 27.3; 95 \% CI: 19.2 - 39.0), having a family member who smokes (OR: 2.9; $95 \%$ CI: 1.6 - 5.5), having a friend who uses tobacco (OR: 1.9; 95 \% CI: $1.2-3.1$ ), and feeling insecure within the family (OR: 2.1; $95 \%$ CI: 1.1 - 3.8). The HosmerLemeshow goodness-of-fit test was not significant $\left(\chi^{2}=2.2\right.$, $p=0.9$ ), indicating the model fit the data well.

\section{Discussion \\ Tobacco use}

The present study is the first large survey focusing on PAS use among middle and high school students in the North Center of Morocco.

The lifetime smoking prevalence among all school students $(16.1 \%)$ reported in this study was slightly lower than the rate $(17.0 \%)$ reported by Mediterranean School Survey Project on Alcohol and Other Drugs (MedSPAD), which is a cross disciplinary survey that was conducted in 
Table 3 Psychoactive substance use and background characteristics

\begin{tabular}{|c|c|c|c|c|c|c|c|c|c|c|c|c|c|}
\hline \multirow{3}{*}{$\begin{array}{l}\text { Background } \\
\text { characteristics }\end{array}$} & \multicolumn{6}{|c|}{ Users } & \multicolumn{6}{|c|}{ Non-users } & \multirow[t]{3}{*}{$p$-value } \\
\hline & \multicolumn{2}{|c|}{ Male } & \multicolumn{2}{|c|}{ Female } & \multicolumn{2}{|c|}{ Total } & \multicolumn{2}{|l|}{ Male } & \multicolumn{2}{|c|}{ Female } & \multicolumn{2}{|l|}{ Total } & \\
\hline & $N$ & $\%$ & $\bar{N}$ & $\%$ & $\bar{N}$ & $\%$ & $N$ & $\%$ & $\bar{N}$ & $\%$ & $\bar{N}$ & $\%$ & \\
\hline \multicolumn{14}{|l|}{ School levels } \\
\hline Intermediate & 98 & 10.5 & 3 & 0,4 & 101 & 6.1 & 836 & 89.5 & 720 & 99.6 & 1556 & 93.9 & $<0.001$ \\
\hline Secondary & 152 & 23.2 & 27 & 3,9 & 179 & 13.4 & 502 & 76.7 & 655 & 96.0 & 1157 & 86.6 & \\
\hline \multicolumn{14}{|l|}{ Age groups (years) } \\
\hline $11-14$ & 13 & 3.2 & 1 & 0,3 & 14 & 1.8 & 387 & 96.8 & 394 & 99.7 & 781 & 98.2 & $<0.001$ \\
\hline $15-18$ & 164 & 17.1 & 23 & 2.6 & 187 & 10.1 & 796 & 82.9 & 865 & 97.4 & 1661 & 89.9 & \\
\hline $19-23$ & 70 & 31.5 & 6 & 5.1 & 76 & 22.4 & 152 & 68.5 & 111 & 94.9 & 263 & 77.6 & \\
\hline \multicolumn{14}{|l|}{ Location } \\
\hline Urban & 190 & 16.9 & 28 & 2.5 & 218 & 9.7 & 935 & 83.1 & 1094 & 97.5 & 2029 & 90.3 & NS \\
\hline Rural & 60 & 12.9 & 2 & 0.7 & 62 & 8.3 & 403 & 87.1 & 281 & 99,3 & 684 & 91.7 & \\
\hline \multicolumn{14}{|l|}{ Parents' marital status } \\
\hline Married & 219 & 15.4 & 22 & 1.8 & 241 & 9.1 & 1201 & 84.6 & 1218 & 98.2 & 2419 & 90.9 & NS \\
\hline Divorced & 9 & 16.9 & 4 & 7.1 & 13 & 11.9 & 44 & 83.1 & 52 & 92.9 & 96 & 88.1 & \\
\hline Widowed & 15 & 20.5 & 2 & 2.9 & 17 & 11.9 & 58 & 79.5 & 68 & 97.1 & 126 & 88.1 & \\
\hline Separated & 4 & 14.3 & 1 & 2.7 & 5 & 7.7 & 24 & 85.7 & 36 & 97.3 & 60 & 92.3 & \\
\hline \multicolumn{14}{|l|}{ Father's education } \\
\hline Illiterate & 77 & 13.1 & 2 & 0.5 & 79 & 7.5 & 514 & 86.9 & 465 & 99.5 & 979 & 92.5 & NS \\
\hline Primary & 72 & 16.9 & 11 & 3.0 & 83 & 10.5 & 353 & 83.1 & 357 & 97.0 & 710 & 89.5 & \\
\hline Secondary & 71 & 19.1 & 10 & 2.5 & 81 & 10.6 & 301 & 80.9 & 381 & 97.5 & 682 & 89.4 & \\
\hline University and above & 23 & 13.2 & 6 & 4.0 & 29 & 9.0 & 151 & 86.8 & 144 & 96.0 & 295 & 91.0 & \\
\hline \multicolumn{14}{|l|}{ Mother's education } \\
\hline Illiterate & 165 & 16.8 & 8 & 1.0 & 173 & 9.6 & 813 & 83.2 & 807 & 99.0 & 1620 & 90.4 & NS \\
\hline Primeray & 29 & 11.2 & 7 & 2.8 & 36 & 7.1 & 231 & 88.8 & 242 & 97.2 & 473 & 92.9 & \\
\hline Secondary & 37 & 14.3 & 10 & 3.9 & 47 & 9.1 & 221 & 85.7 & 248 & 96.1 & 469 & 90.9 & \\
\hline University and above & 13 & 17.1 & 4 & 5.5 & 17 & 11.4 & 63 & 82.9 & 69 & 94.5 & 132 & 88.6 & \\
\hline \multicolumn{14}{|l|}{ Father employment } \\
\hline Employed & 204 & 15.2 & 26 & 2.3 & 230 & 9.3 & 1136 & 84.8 & 1101 & 97.7 & 2273 & 90.7 & NS \\
\hline unemployed & 8 & 18.2 & 0 & 0.0 & 8 & 9.9 & 36 & 81.8 & 37 & 100.0 & 73 & 90.1 & \\
\hline Retired & 19 & 17.2 & 1 & 0.8 & 20 & 8.2 & 91 & 82.8 & 133 & 99.2 & 224 & 90.8 & \\
\hline \multicolumn{14}{|l|}{ Mother employment } \\
\hline Employed & 18 & 12.8 & 9 & 6.4 & 27 & 9.6 & 123 & 87.2 & 131 & 93.6 & 254 & 90.4 & NS \\
\hline unemployed & 218 & 15.4 & 19 & 1.5 & 237 & 8.9 & 1195 & 84.6 & 1231 & 98.5 & 2426 & 91.1 & \\
\hline \multicolumn{14}{|l|}{ Family income } \\
\hline$\leq 300 £$ & 58 & 20.5 & 4 & 1.9 & 62 & 12.6 & 225 & 79.5 & 205 & 98.1 & 430 & 87.4 & $<0.007$ \\
\hline $301-1000 £$ & 165 & 14.3 & 24 & 2.2 & 189 & 8.4 & 990 & 85.7 & 1081 & 97.8 & 2071 & 91.6 & \\
\hline$\geq 1000 £$ & 21 & 18.3 & 1 & 1.4 & 22 & 11.8 & 94 & 81.7 & 71 & 98.6 & 165 & 88.2 & \\
\hline
\end{tabular}

NS Not significant $p<0.05$

Moroccan schools in 2013 among 5801 school students [11]. Considering only the results for subjects aged 13-15 years, the prevalence of current tobacco use was $4.0 \%$. This rate was lower than the findings reported by the Global School-based Student Health Survey (GSHS) conducted in
Morocco and other nearby countries among students aged 13-15 years. The 2010 Morocco GSHS, which was conducted among 2924 students, indicated that the prevalence of current smoking cigarettes was $5.2 \%$ [12]. In Tunisia, $7.5 \%$ of students who participated in the 2008 GSHS, 
Table 4 Univariate and multivariate logistic regression analysis for psychoactive substance use related factors among participants

\begin{tabular}{|c|c|c|c|c|c|c|}
\hline \multirow[b]{2}{*}{ Category } & \multicolumn{3}{|c|}{ Univariate $^{\mathrm{a}}$} & \multicolumn{3}{|c|}{ Multivariate $^{\mathrm{b}}$} \\
\hline & OR & $95 \% \mathrm{Cl}$ & $p$-value & OR & $95 \% \mathrm{Cl}$ & $p$-value \\
\hline \multicolumn{7}{|l|}{ Gender } \\
\hline Female & 1 & & & 1 & & \\
\hline Male & 8.5 & $5.8-12.6$ & $<0.001$ & 1.9 & $1.1-2.7$ & $<0.05$ \\
\hline \multicolumn{7}{|l|}{ School levels } \\
\hline Intermediate & 1 & & & 1 & & \\
\hline Secondary & 2.3 & $1.8-3.1$ & $<0.001$ & 2.8 & $1.6-4.8$ & $<0.001$ \\
\hline \multicolumn{7}{|c|}{ Age groups (years) } \\
\hline $11-14$ & 1 & & & 1 & & \\
\hline $15-18$ & 2.5 & $1.9-3.4$ & $<0.001$ & 1.0 & $0.3-3.4$ & NS \\
\hline $19-23$ & 16.1 & 8.9-29.4 & $<0.001$ & 1.1 & $0.6-2.1$ & NS \\
\hline \multicolumn{7}{|l|}{ Feel secure } \\
\hline Yes & 1 & & & 1 & & \\
\hline No & 2.1 & $1.6-2.8$ & $<0.001$ & 2.1 & $1.1-3.9$ & $<0.02$ \\
\hline \multicolumn{7}{|c|}{ Smoking tobacco } \\
\hline No & 1 & & & 1 & & \\
\hline Yes & 46.6 & $33.4-65.2$ & $<0.001$ & 27.3 & $19.2-39.0$ & $<0.001$ \\
\hline \multicolumn{7}{|c|}{ Family member who smoke } \\
\hline No & 1 & & & 1 & & \\
\hline Yes & 2.3 & $1.3-3.9$ & $<0.002$ & 2.9 & $1.6-5.5$ & $<0.001$ \\
\hline \multicolumn{7}{|c|}{ Friends who smoke } \\
\hline No & 1 & & & 1 & & \\
\hline Yes & 1.9 & $1.3-3.0$ & $<0.002$ & 1.9 & $1.2-3.1$ & $<0.005$ \\
\hline
\end{tabular}

OR Odds ratio

$95 \% \mathrm{Cl} 95 \%$ confidence intervals

$p<0.05$

a Univariate associations between PAS use and sociodemographic variables and tobacco use were assessed using the chi-square test

${ }^{b}$ Variables with $p \leq 0.20$ on univariate analysis were entered in multivariate stepwise logistic regression model

The Hosmer-Lemeshow goodness-of-fit test was used to evaluate multivariate model fit $\left(\mathrm{X}^{2}=2.2, p=0.9\right)$

reported the use of tobacco one or more days during the past 30 days [13]. In Algeria, the 2011 GSHS, which was conducted among 4532 school students, estimated that the prevalence was $9.2 \%$ [14]. The 2010 Mauritania GSHS revealed that $17.3 \%$ of school students were currently tobacco users [15]. Low tobacco use rate among school students in the North Center of Morocco could be related mostly to the social and family values in conservative societies, which frown upon tobacco use especially among adolescents.

\section{Cannabis use}

Cannabis recorded the highest lifetime prevalence among illicit drugs $(8.1 \%)$; its prevalence in the last 12 months and in the last 30 days was 6.7 , and $5.6 \%$, respectively. These rates were very close to those reported by the national survey 2013 MedSPAD (the life time, the last 12 months, and the last 30 days prevalence were respectively, 9.0, 6.0 and $6.0 \%$ ) [11]. Regarding school students aged 13-15 years, the life time prevalence of cannabis $(2.8 \%)$ was almost similar to 2010 Morocco GSHS (3.0\%) [12].

In our sample, cannabis is the most-used substance after tobacco. Despite its legal prohibition, cannabis is widely used among Moroccan youth. The availability and accessibility of cannabis can be explained by the fact that Morocco is one of the main producers of cannabis resin in the world. Nevertheless, it appears that cannabis use rates in Morocco are much lower than the rates found among European and American youth. In Europe, 14.6 million or $11.2 \%$ of young adults (15-34) used cannabis in the last year [16]. In North America, annual prevalence of cannabis use is approximately $10.7 \%$ in population aged 15-64, and has increased among youth over the past four years [17].

\section{Alcohol use}

After tobacco and cannabis, the most commonly used substance in our sample is alcohol. These findings were consistent with what was reported by the National Observatory of drugs and addictions in 2014 [4]. Still, the lifetime, annual and past month rates $(4.3,3.7$, and $3.2 \%$ respectively) announced by the present study, were lower than national prevalence $(8.0,5.0$, and $5.0 \%$ respectively) [11]. The comparison with other Arab countries was difficult because recently measured prevalence rates are not always available. Nevertheless, it appears that alcohol use among Moroccan school students falls in middle grounds in relation to other neighboring countries. In Tunisia, the national survey conducted in 2008 among middle school students revealed that $3.8 \%$ of adolescents used alcohol and other drugs once or more times during their life [13]. The past month prevalence of alcohol among school students in Syria and Lebanon in 2010/11 was 7.4 and $28.5 \%$, respectively $[18,19]$.

According to the world health organization (WHO), the lowest prevalence rates of heavy episodic drinking among adolescents aged 15-19 in the world for 2010, were recorded in Muslim countries located in the Eastern Mediterranean Region, such as Morocco [20], which can be relegated to alcohol religious prohibition.

\section{Other psychoactive substances use}

The present study showed that the lifetime prevalence of inhalants, psychotropic substances without medical prescription, cocaine, heroin and amphetamine use were $1.7,1.0,0.7,0.3$, and $0.2 \%$ respectively. Comparing the prevalence of inhalants and amphetamine use with other regions of Morocco was not possible because of the 
dearth of research on the use of these substances among Moroccan school students.

On the other hand, the lifetime prevalence for cocaine and heroin use reported by this study was lower than the rate estimated by the 2013 national survey (cocaine $1.3 \%$, heroine $1.2 \%$ ) [11]. Generally, the prevalence of cocaine and heroin use among Moroccan school students remain lower than the rates found in some Arab countries like Lebanon, and much lower than those reported among European youth $[11,16]$. The plausible reason for this low prevalence might be related to financial and accessibility considerations. As a matter of fact, Moroccan students don't have enough money, or easy access to cocaine and heroin. Contrariwise, the most used substances by Moroccans students (tobacco, cannabis and alcohol) were the most available and the most accessible PASs.

For the consumption of psychotropic substances without medical prescription, the rate found in this study $(1.0 \%)$ was lower than the national lifetime prevalence (5.0 \%) [11]. Moreover, our results did not show gender differences concerning the preference of psychotropic substances without medical prescription conversely to the findings of five recently surveyed countries (Australia, United States of America, Spain, Urban Afghanistan, and Pakistan), which reported that the non-medical use of pharmaceutical drugs was nearly equivalent, not to say higher among women [21, 22]. Likewise, the national survey conducted in Morocco in 2009 indicated that the prevalence of tranquillizers or sedatives use without doctors' prescriptions exceeded the rate of cannabis use among Moroccan females aged 15-17 [23]. Similarly, in Algeria, there was an evident preference for psychotropic drugs among females 15-16 years old, which did not only exceed cannabis use but also alcohol and tobacco use as well [24]. The fact that psychotropic drugs were first in use among girls might suggest that social acceptance and accessibility of such drugs (a prescription issued by an obliging doctor) fostered this consumption preference among girls.

\section{Risk factors of psychoactive substances use}

Our results demonstrated that the potential risk factors of PASs use included gender, school levels, age groups, smoking tobacco status, friends and family member smoking status, and feelings of insecurity within family.

In the present study, males were more likely to use PASs than females. For lifetime, annual and past-month prevalence of the use of the entire studied PASs, the rates reported among males were significantly higher than females. These findings confirmed national findings that there was a predominance of PASs use among boys [11], and international findings that nearly all drug use surveys indicated that male-female differences in the use of alcohol and drugs occurred in most countries, with males being more likely than females to use at all [21, 25-27]. However, it should be noted that in Morocco, the use of PASs among females has been associated with social stigmatization. Smoking or using drugs is still seen as shameful and inappropriate. As a result, females are not likely to report their use of PAS honestly, and this is probably the source of bias which could drastically underestimate the prevalence of PAS use among females.

In terms of other determinants of PAS use, we observed that the prevalence of PASs use was correlated positively with age. This result was consistent with what was often reported in developing countries [28]. For the mean age of onset of PAS, we found that the average was 14 years, which means that young people initiate PASs use during late middle school and early high school [29]. Early initiation of substances can lead to the host of current and future substance use problems such as poor school performance, school drop-out or delinquency, health problems, and future risks for substance use disorders [30, 31].

Results of the present study indicated that students consumption of PASs was related to smoking status; current tobacco users were at higher risk of PASs use than non-users $(\mathrm{OR}=27.3)$. In fact, the temporal sequencing of PASs use, as it was observed across several epidemiological samples, is cigarettes and alcohol initiation, followed by cannabis, and finally other PASs. Such a finding points to the pivotal role of early initiation of cigarette or alcohol use on subsequent PASs use [32, 33].

This study indicated that PAS use by friends and family member, alongside with feelings of insecurity within the family were significant risk factors $\left(\mathrm{OR}_{1}=1.9, \mathrm{OR}_{2}=\right.$ 2.9 , and $\mathrm{OR}_{3}=2.1$, respectively). These results have been congruent with those of previous studies that have showed that social factors are important determinants of the risk of PASs experimentation, regular use, and addiction in adolescence. Risk factors such as family dysfunction, bad relationship with parents, having family member who used PASs, or being friends with smokers or users of PASs are more decisive in the overall intensity of PASs use in males than in females [34].

We note some limitations to this study. First, PASs use was self-reported, which could be subject to social desirability bias. Since PASs use is a taboo practice in the Moroccan conservative society, and constitutes a felony under the Moroccan law, there is a risk of underreporting among school students generally and females particularly when using self-report questionnaires. Although we went to great lengths to ensure confidentiality and anonymity, we could not assess underreporting of substance use. The prevalence reported above may thus represent low estimates of the actual prevalence. Second, the study was cross-sectional, which limits the extent to which 
conclusions can be drawn about the causal nature of the associations between the correlates and PASs use.

Concerning the strengths of the present study, it includes a large representative sample. It is the first study of its kind to be performed among middle and high school students in the North Center of Morocco with the aim of investigating the prevalence and exploring the risk factors of PASs use.

\section{Conclusion}

Our data maintain the idea that many students initiate PASs consumption during late middle school and early high school. As vindicated throughout our findings, current tobacco users were at higher risk of PASs use than nonusers. The presented results call attention to the urgent need of implementing prevention strategies at an early age. Hence, the first step to counteract the PASs abuse is to spread awareness against tobacco consumption. Monitoring PASs use among Moroccan school students is essential to study risky behaviors among adolescents and provide a pointer to potential future trends.

\section{Additional file}

Additional file 1: English version of the questionnaire. (DOCX $27 \mathrm{~kb}$ )

\section{Abbreviations}

GSHS, Global school health survey; MedSPAD, Mediterranean School Survey Project on Alcohol and Other Drugs; PASs, Psychoactive substances

\author{
Acknowledgment \\ We are grateful to all students who participated in the study, data collectors, \\ and supervisors. \\ We would also like to thank Ms. El Kinany Soukaina, Ph.D student in English \\ department for her help for reviewing the manuscript.
}

\section{Funding}

Sincere thanks go to Hassan the 2nd University Hospital Center, Faculty of Medicine and Pharmacy of Fez, University Sidi Mohammed Ben Abdallah for funding this study.

\section{Availability of data and materials}

Data will not be shared, because there are other findings expected to be exploited in other publications.

\section{Authors' contributions}

BZ has contributed to conception and design, acquisition of data, analysis and interpretation of data and has been involved in drafting the manuscript; $\mathrm{BB}$ has contributed to acquisition of data; AE has been involved in analysis and interpretation of data, and has been involved in revising the manuscript critically; SA has been involved in analysis and interpretation of data, and has been involved in revising the manuscript critically; IR has contributed to conception and design, and acquisition of data; RA has contributed to conception and design, and acquisition of data; BL has contributed to conception and design of data; SK has contributed to acquisition of data; $A B$ has contributed to acquisition of data; NB has contributed to acquisition of data; HH has contributed to acquisition of data; AN has been involved in analysis and interpretation of data; CN has contributed to conception and design, and acquisition of data; KE has contributed to conception and design, has been involved in revising the manuscript critically and has given final approval of the version to be published. All authors read and approved the manuscript.

\section{Competing interests}

The authors declare that they have no competing interests.

Consent for publication

Not applicable.

\section{Ethics approval and consent to participate}

Ethical clearance was acquired from the ethical committee of the Faculty of Medicine and Pharmacy in Fez city. The questionnaires were administered upon receiving school-directors permissions and written informed consent from all participants. Concerning the students under the age of 16, written informed consents from the parents were also obtained. The process of contacting parents was facilitated through parents' associations.

\section{Author details}

${ }^{1}$ Laboratory of Epidemiology, Clinical Research, and Health Community, Faculty of Medicine and Pharmacy, Sidi Mohammed Ben Abdallah University, Fez, Morocco. ${ }^{2}$ Laboratory of Physiology-Pharmacology and Environmental Health, Dhar El Mahraz Faculty of Sciences, Sidi Mohammed Ben Abdallah University, Fez, Morocco. ${ }^{3}$ Unit of Toxicology, Hassan the 2nd University Hospital Center, Fez, Morocco. ${ }^{4}$ Laboratory of Clinical Neurosciences, Faculty of Medicine and Pharmacy, Sidi Mohammed Ben Abdallah University, Fez, Morocco. ${ }^{5}$ Service of Psychiatry, Ibn Al Hassan Hospital, Hassan the 2nd University Hospital Center, Faculty of Medicine and Pharmacy, Sidi Mohammed Ben Abdallah University, Fez, Morocco.

Received: 4 April 2015 Accepted: 24 May 2016

Published online: 04 June 2016

\section{References}

1. United Nations Office on Drugs and Crime (UNODC). World drug report. New York: United Nations; 2015.

2. Odejide AO. Status of drug use/abuse in Africa: a review. Int J Ment Health. 2006:4:87-102.

3. Moussaoui D. La santé mentale au Maroc : enquête nationale sur la prévalence des troubles mentaux et des toxicomanies. L'Encéphale. 2007;4(Suppl):S125-6.

4. L'Observatoire National des Drogues et Addictions (ONDA). Rapport annuel de 2014 de. In: I'Observatoire National des Drogues et Addictions. 2014. http:// www.onda-drogues.com/index.php/fr/rapports [Accessed on 2015 Nov 5].

5. United Nations Office on Drugs and Crime (UNODC). Morocco cannabis survey 2003, Executive Summary. 2003. https://www.unodc.org/pdf/ publications/morocco_cannabis_survey_2003_exec_sum.pdf. [Accessed 3 Jun 2016].

6. United Nations, office on drugs and crime (UNODC). Cannabis in Africa, an overview. 2007.

7. United Nations Office on Drugs and Crime (UNODC). Morocco cannabis survey 2005, Executive Summary. 2007. https://www.unodc.org/pdf/ research/Morocco_survey_2005_ex_sum.pdf [Accessed on 5 Nov 2015].

8. World Health Organization. Global School-based Student Health Survey: Morocco, Fact Sheet. 2006. http://www.who.int/chp/gshs/2006_Morocco_ Fact_Sheet.pdf. [Accessed on 25 Feb 2015 ].

9. Saifuddin Ahmed. Methods in Sample Surveys, Cluster Sampling. Johns Hopkins University, 2009

10. Slama K. Tobacco control and prevention: A guide for low-income countries. Paris: IUATLD (International union against tuberculosis and lung disease); 1998.

11. El Omari F, Sabir M, Toufiq J. L'usage de drogues auprès des élèves marocains. Rapport MedSPAD. 2013.

12. World Health Organization. Global School-based Student Health Survey: Morocco, Fact Sheet. 2010. http://www.who.int/chp/gshs/Morocco_2010_ GSHS_FS.pdf [Accessed on 25 Feb 2015].

13. World Health Organization. Global School-based Student Health Survey: Tunisia, Fact Sheet. 2008. http://www.who.int/chp/gshs/Tunisia_2008_Fact_ Sheet.pdf [Accessed on 25 Feb 2015].

14. World Health Organization. Global School-based Student Health Survey: Algeria, Fact Sheet. 2011. http://www.who.int/chp/gshs/2011_GSHS_FS_ Algeria.pdf [Accessed on 25 Feb 2015].

15. World Health Organization. Global School-based Student Health Survey: Mauritania, Fact Sheet. 2010. http://www.who.int/chp/gshs/Mauritania 2010_FS.pdf [Accessed on 25 Feb 2015]. 
16. European Monitoring Centre for Drugs and Drug Addiction (EMCDDA). European drug report 2014: trends and developments. Lisbon: EMCDDA; 2014

17. SAMHSA. National Household Survey on Drug Use and Health. NIDA: Monitoring the Future; 2010.

18. World Health Organization. Global School-based Student Health Survey: Syria, Fact Sheet. 2010. http://www.who.int/chp/gshs/Syria_2010_GSHS_FS. pdf [Accessed on 26 Feb 2015].

19. World Health Organization. Global School-based Student Health Survey. Lebanon: Fact Sheet; 2011.

20. World Health Organization. Global status report on alcohol and health. In: WHO Library Cataloguing-in-Publication Data. 2014.

21. United Nations Office on Drugs and Crime (UNODC). World drug report. New York: United Nations; 2014.

22. Hibell B, Guttormsson U, Ahlström S, Balakireva O, Bjarnason T, Kokkevi A, Kraus L. The 2011 ESPAD Report Substance Use Among Students in 36 European Countries. 2012. The Swedish Council for Information on Alcohol and other Drugs (CAN), The European Monitoring Centre for Drugs and Drug Addiction (EMCDDA), Council of Europe, Co-operation Group to Combat Drug Abuse and Illicit Trafficking in Drugs (Pompidou Group).

23. Council of Europe, Pompidou Group, MedNET Network. Drug use in Moroccan schools: MedSPAD 2009-2010 report. Document PG/Med. 2011. 17, June 2011.

24. Council of Europe, Pompidou Group. First results of the MedSPAD Algeria survey. 2006.

25. Mental Health Evidence and Research, \& Department of Mental Health and Substance Abuse. Disease control priorities related to mental, neurological, developmental and substance abuse disorders. Geneva: World Health Organization; 2006.

26. Holmila M, Raitasalo K. Gender differences in drinking: Why do they still exist? Addiction. 2005;100:1763-9.

27. Moon DG, Hecht ML, Jackson KM, Spellers RE. Ethnic and gender differences and similarities in adolescent drug use and refusals of drug offers. Substance Use \& Misuse. 1999;34:1059-83.

28. Faeh D, Viswanathan B, Chiolero A, Warren W, Bovet P. Clustering of smoking alcohol drinking and cannabis use in adolescents in a rapidly developing country. BMC Public Health. 2006:6:169.

29. Wittchen HU, Behrendt S, Hofler M, Perkonigg A, Lieb R, Buhringer G, Beesdo K. What are the high risk periods for incident substance use and transitions to abuse and dependence? Implications for early intervention and prevention. International Journal of Methods in Psychiatric Research. 2008; 17 Suppl 1:S16-29.

30. Brook JS, Adams RE, Balka EB, Johnson E. Early adolescent marijuana use: risks for the transition to young adulthood. Psychological Medicine. 2002;32:79-91.

31. Miller JW, Naimi TS, Brewer RD, Jones SE. Binge drinking and associated health risk behaviors among high school students. Pediatrics. 2007;119:76-85.

32. Kandel D. Stages and Pathways of Drug Involvement. New York, NY: Cambridge University Press; 2002

33. Wagner FA, Velasco-Mondragon HE, Herrera-Vazquez M, Borges G, LazcanoPonce E. Early alcohol or tobacco onset and transition to other drug use among students in the state of Morelos, Mexico. Drug and Alcohol Dependence. 2005;77:93-6.

34. Lopes GM, Nóbrega BA, Del Prette G, Scivoletto S. Use of psychoactive substances by adolescents: current panorama. Revista Brasileira de Psiquiatria. 2013;35 Suppl 1:S51-61.

\section{Submit your next manuscript to BioMed Central and we will help you at every step:}

- We accept pre-submission inquiries

- Our selector tool helps you to find the most relevant journal

- We provide round the clock customer support

- Convenient online submission

- Thorough peer review

- Inclusion in PubMed and all major indexing services

- Maximum visibility for your research

Submit your manuscript at www.biomedcentral.com/submit

C Biomed Central 